\title{
Entre a prática, a teoria, a escrita e a experimentação etnográficas
}

Dol

http://dx.doi.org/10.11606/ 1678-9857.ra.2020.177099
Entrevista com Michael Taussig

A entrevista que se segue foi realizada no dia 11 de março de 2020, na cidade de Nova lorque, nos Estados Unidos. No dia anterior, o presidente Donald Trump havia reconhecido o status de pandemia de COVID-19 e a quantidade crescente de casos nos Estados Unidos. Enquanto isso, eu estava nos últimos dias de um intercâmbio intelectual de 10 meses (entre maio de 2019 e março de 2020), financiado pela Fapesp, no qual fui supervisionada pelo professor Michael Taussig'. A ideia para esta entrevista surgiu de uma conjunção de fatores, mas especialmente do canal de diálogo aberto com o professor Taussig nos meses anteriores.

A iniciativa de ir para a Columbia University (e para o Institute of Latin American Studies - ILAS) surgiu pelo encantamento com a obra de Taussig. Suas proposições sobre violência e terror me acompanham já há alguns anos, com destaque para o que ele chamou, em Xamanismo, colonialismo e o homem selvagem, de "cultura do terror" e "espaço da morte". Ao me dedicar ao entendimento das formas públicas e privadas de violência em favelas do Rio de Janeiro, estes dois conceitos se tornaram fundamentais para as análises empreendidas.

A obra de Taussig me fascinava também por outros motivos. Destaco, sobretudo, a inventividade e o caráter transgressor de suas propostas que fornecem insights teóricos e metodológicos. Sobretudo, Taussig nos provoca a experimentar etnograficamente, ao mesmo tempo em que mostra a importância de discussões teóricas densas. Sempre li suas obras como repletas do que chamei na entrevista de "amor e deferência pela curiosidade antropológica".

A seu convite, acompanhei, entre setembro e dezembro de 2019, o curso "Taboo and Transgression", que ofereceu no departamento de Antropologia da Columbia University. A experiência de vê-lo lecionar tornou ainda mais instigante o esforço de embarcar em suas propostas e foi algo que iluminou a feitura desta entrevista,
ENTREVISTADORA

1 | Class of 1933 Professor of Anthropology - Columbia University in the City of New York. 
como ficará claro. Com ele e por meio dele, pude revisitar autores clássicos como Walter Benjamin, Georges Bataille (e friso que ele é um exímio leitor de ambos), Marcel Mauss, Jane Gallop e Angela Carter, bem como me lançar à descoberta de outras referências como Maggie Nelson, Daniella Gandolfo e Leo Steinberg. Após cada encontro semanal, saía com a cabeça fervilhando, instigada por tantas questões. Além disso, o final de todas as aulas era dedicado a experimentos corporais coletivos, em que descobrimos nossos corpos e seus movimentos possíveis (no que Taussig chamou de "stimulate alternative forms of writing, exploring style, 'voice', rhythm, and form"). Dança como "escrita" e como "interpretação" e como forma de desafiar e transgredir as fronteiras formais e canônicas da disciplina e do espaço da sala de aula. Para mim, pelo menos, este foi um dos maiores aprendizados e um convite a sempre experimentar, desafiar, transgredir.

Assim, essa entrevista ${ }^{2}$ é fruto de minha leitura da obra de Taussig, bem como das trocas e conversas que estabelecemos. A tentativa foi de mapear temas que aparecem em seus escritos, bem como abrir caminho para as discussões de seu novo livro, lançado em julho de 2020. Busquei articular as perguntas de forma a apresentar um panorama de seus livros, a partir das questões e dúvidas que eles suscitaram. Dentre os temas abordados, destaco: a prática e a escrita da etnografia (e as experimentações possíveis), os desafios de lidar com as violências, a ideia de "domínio do não-domínio" e conceitos como o de sistema nervoso, mimesis e transgressão.

Agradeço imensamente ao professor Taussig pela generosidade de ter me recebido como Visiting Scholar na Columbia University e, por, mesmo em meio ao estágio inicial da pandemia, ter me concedido esta entrevista. Minha gratidão e minha admiração são constantes. Que esta entrevista seja tão desafiadora e instrutiva para os leitores como foi para mim e, sobretudo, um convite a experimentar em nossas pesquisas e em nossas atividades acadêmicas, como ele tem feito com maestria ao longo dos anos.

1 - De minha perspectiva, você está sempre tentando questionar a prática e a escrita etnográficas. Você traz nos seus textos uma ampla gama de referências, além de experimentar com a escrita. Em Walter Benjamin's Grave, por exemplo, você confessa a sua paixão pela contação de história - "uma narrativa silenciada e imperfeita", como você diz - e defende que essa narrativa como uma forma de análise. Ao fazê-lo, creio que nos desafia a ir além das definições clássicas da antropologia e, ao mesmo tempo, sinto que é uma deferência constante, um amor pela curiosidade antropológica e pelo fazer etnográfico. Você pode nos dizer mais sobre esse amor?

MT | Com certeza! É estranho, não é? Soa até esquizofrênico. Por um lado, essa é uma forma de desafiar, uma crítica, e ao mesmo tempo, um certo endosso de tudo o que os antropólogos fazem. Se compararmos a antropologia e o jornalismo, ambos têm como foco os eventos íntimos de pequena escala, os aspectos

\footnotetext{
2 | Em termos técnicos, gostaria de salientar o desafio de traduzir Taussig para o português. Para este fim, contei com a inestimável parceria de Juliana Valente (Graduate Center-CUNY) e com a revisão e transcrição de Renata Ferreira.
} 
minuciosos dos eventos, sejam eles grandes ou pequenos. Mas a antropologia sempre tem um outro olhar, direcionado para dar atenção às questões da teoria social e filosófica, e assim por diante, que, claro, os jornalistas não conseguem fazer, não de forma profunda, na sua escrita. A antropologia está em um bom lugar, eu acredito, entre o íntimo e o filosófico, e é disso que eu gosto. Existem muitas disputas ou problemas suscitados, ao longo da minha vida, sobre a antropologia se deter muito à teoria ou aos fatos. Revisitando essas questões, isso é de se esperar, porque há sempre um conflito entre a experiência de campo e o amor pela teoria de como a sociedade se deu como tal.

2 - Em muitos dos seus textos, nós encontramos palavras como cura, redenção, ornamento, fetiche, mimetismo e (a minha favorita) transgressão. Todas elas estão relacionadas não só com o dado etnográfico, mas com a etnografia em si. Pensando nos seus livros, existem experimentações, como a publicação de um diário de campo (Law in a Lawless Land), dos desenhos que você realizou enquanto estava em campo (The Magic of the State, I Swear I Saw This e The Corn Wolf). Muitas fotografias no livro My Cocaine Museum. E na sua escrita existe não só um rigor teórico (como verdadeiras aulas sobre Benjamin, Marx, Bataille, Artaud, Nietzsche, Freud, Wittgenstein, por exemplo), mas um questionamento constante, um tom que é simultaneamente sarcástico e com um teor de humor. Como você enxerga esses três eixos: conteúdo, forma e estilo?

MT | Bom, você descreveu, muito bem ao meu ver, o que eu tentei fazer. Eu acredito que muitas pessoas não falam sobre o humor, ou a tentativa de humor, e isso é algo que genuinamente tento fazer. Portanto, fico feliz que você identificou isso. As palavras- chave que você mencionou são, me parece, bem constantes... Acredito que provavelmente eu exagere um pouco. Mas eu fico sempre tão impressionado de como as formas pelas quais falamos de sociedades, de grupos, de seres humanos é informada por forças subliminares. E essa força subliminar parece ser, ao meu ver, algo muito parecido com o que é genuinamente descrito como a magia. Portanto, eu vejo que a escrita, da minha parte, é uma conversa com esse nível subliminar, com essa magia, que está posicionada sobre uma contra-magia. Isso então leva ao meu interesse pelo estilo, um interesse pela estética, que eu vejo como sendo o aspecto de poder em todo os lugares, a todo momento. Algo que é crucial, mas genuíno e completamente ignorado por boa parte das Ciências Sociais. Então, isso é algo que é muito importante para mim. Eu falo na arte versus a arte. Com isso, eu quero dizer que praticamos uma arte que pode ir de encontro à arte do status quo, ou seja, argumentos sobre a boa vida, argumentos sobre equidade, argumentos para justificar a hierarquia, a autoridade e o domínio parecem funcionar sob minha perspectiva, porque eles têm uma força estética, eles têm força mítica e 
simbólica. Então, o meu trabalho como antropólogo é fornecer uma nova arte, uma nova cultura se quiser, contra isso, mas ambas estão entrelaçadas, e por isso tenho essa frase, da arte versus a arte, em vez de dizer a economia versus a ideologia, ou uma ideologia versus outra ideologia. Não. O que eu acredito que transcende tudo isso é uma forma de estética, uma estética versus outra estética. Eu estou lendo essa biografia extensa que saiu recentemente sobre a Susan Sontag e estou curioso de ver que esse é basicamente o seu posicionamento: a estética, a importância política central da estética.

3 - Como eu já lhe disse antes, se tivesse que escolher alguma questão na sua obra seria a ideia de transgressão, porque acho que você transgride pensando em metodologia, com um foco na escrita e como uma questão teórica. No meu entendimento, Bataille é uma referência central para você nessa discussão sobre a transgressão, associada à ideia de "sociologia sagrada". E sagrado para ele está relacionado ao sacrifício, ou à consagração daquilo que foi destruído. Você acha possível pensar em uma "sociologia sagrada" hoje? Como podemos traduzir a transgressão para um mundo contemporâneo de novas (ou talvez não tão novas) formas de terror e violência?

MT|Esta é uma grande pergunta! Bataille realmente era parte de um grupo. Portanto, não é apenas Bataille. Tem a sua companheira, Laure (Collete Peignot), que morreu muito jovem, tem Michel Leiris, e o brilhante Roger Caillois, só para começar. Se você olhar para quem escreveu para o Collège of Sociologie, você verá muitas pessoas envolvidas naqueles anos, 1937 a 1939. Então, acho que isso é importante de lembrar.O que seria uma sociologia sagrada hoje? Eu acho que você está fazendo uma pergunta essencial. Bom, eu comecei a pensar nisso pela primeira vez quando li o livro do Jacobo Timerman, sobre seu encarceramento na Argentina. Em inglês, o título da obra é Prisoner Without a Name, Cell Without a Number. Essa para mim parece ser uma avaliação muito concreta, uma afirmação muito concreta sobre o lugar do sagrado na repressão política. O regime militar, o seu fetiche com o comunismo, a homossexualidade e os judeus, por exemplo. Segundo, lendo esse livro, você precisa refletir sobre o papel da tortura. E quando você começa a pensar na tortura de alunos do colegial, de mulheres, especialmente na Argentina, você não consegue parar de pensar na tortura em toda a América Latina, em todo o mundo, e isso fica cada vez maior, pensando na guerra do George Bush contra o Iraque, ou depois de 11 de setembro, nas prisões clandestinas da $\mathrm{ClA}$ em diversos lugares no mundo. O debate sobre a tortura nesse país que ganhou força com o Trump, que é favorável à tortura. Então as perguntas para mim eram: se a tortura era realizada para se conseguir informação, como geralmente se diz; ou se ela é 
feita em razão de algum prazer psicológico, alguma forma de prazer sadista? $\mathrm{Ou}$, e/ou, se ela tem a sua própria qualidade de ritual religioso sagrado? Agora, essa terceira pergunta é a mais inovadora, e facilmente a pergunta que nunca é feita ou é realizada com menos frequência. Sobre as outras, muito já foi escrito e dito sobre o assunto. Me parece que, claro, vez ou outra há alguma informação valiosa, mas ela é muito exagerada. A tortura realmente é feita por alguma outra série de motivações. E essas motivações têm relação com a expiação, expiar o mundo do demônio, expiar o mundo da peste, expiar o mundo do comunismo, da homossexualidade, da sexualidade em geral, e assim por diante. Ou seja, no sentido negativo, esse é o seu papel, esse é o conhecimento fornecido pela sociologia sagrada. Sociologia sagrada, como foi cunhado pelo Collège, foi uma tentativa de pensar sobre as lições fornecidas pelos estudos de religião nas sociedades primitivas. A feitiçaria, por exemplo, o fetichismo aplicado à sociedade moderna, enquanto o movimento nazista aumentava seu vigor, enquanto os nazistas invadiam a França, enquanto a maioria da população francesa se tornou colaboradora. Depois vão dizer que a França liderou a resistência, mas isso é uma mentira. Mesmo essas forças, o antissemitismo, a exaltação do primitivo pelos nazistas, aqui novamente temos um exemplo da "arte contra a arte". O Collège de Sociologie tenta, usando Durkheim em particular, criar uma resposta para essa força massiva, que eu acho que vemos no Brasil e em boa parte do mundo com a hostilidade contra imigrantes na Europa... Coisas que vão piorar com o coronavírus. Portanto, as forças que foram desencadeadas por crises, por coup d'états, o que vemos nos EUA, particularmente na fronteira com o México e a campanha contra os muçulmanos, têm relação com a evocação, eu acredito, da sociologia sagrada. É como se o governo estivesse utilizando a sociologia sagrada (risos). Portanto, nós também, ou eu também. A sociologia sagrada também é importante em outro sentido, na sua relação com o heteronormativo, o heterogêneo versus o homogêneo, e assim por diante. É uma visão diferente da forma como as sociedades se constituem em grupos. Ela enfatiza a sua natureza fragmentada, se quiser assim dizer, da realidade e do poder. Benjamin em Theses on the Philosophy of History $y^{3}$ tem coisas importantes a dizer sobre o heterogêneo versus o homogêneo quando ele fala sobre a visão da história em que o heterogêneo surge e desloca o homogêneo.

3| Traduzido no Brasil como "Teses de filosofia da História" ou "Sobre o conceito de História". Eu diria que esse também é um exemplo da sociologia sagrada. Benjamin, você sabe, participou de algumas das reuniões do Collège e, de acordo com um observador, ficou deslumbrado. E seu amigo e colega Adorno ficou bastante desconfiado, na verdade, do Collège. Ele está em uma comissão com fascistas, particularmente Caillois. Esteé o perigo. Uma vez que você se envolve, uma vez que você endossa esta pergunta sobre o sagrado e a sociologia você caminha numa linha tênue entre o fascismo e o antifascismo. 
4-A literatura é uma das suas maiores influências. Nós temos uma gama de autores da literatura que você usa para discutir a antropologia. Nos anos 80 , havia diversos questionamentos sobre questões como a representatividade, a autoridade etnográfica, a escrita etnográfica. George Marcus e James Clifford chamaram isso de poética e política da etnografia. Acredito que na sua obra conseguimos encontrar ambas-a poética e a política -, mas de forma um pouco diferente. Eu acredito que seu trabalho seja mais experimental. Você concorda com essa definição?

MT | Eles propuseram e eu fui lá e fiz. Eles mantiveram uma fé pela empreitada acadêmica, enquanto acho que eu não tinha. Se eles não tivessem iniciado esse processo onde estariam as pessoas como eu? Provavelmente não teríamos publicado. Então, isso é muito, muito crucial. O trabalho que eles fizeram é sofisticado e requer uma leitura abrangente. Clifford tem dois textos ${ }^{4}$ em particular, um sobre a autoridade etnográfica e outro sobre o surrealismo etnográfico. Quero dizer, eles são verdadeiras obras-primas. Eles irão durar para sempre.

Mas, para você, essas experimentações foram sempre intencionais? Esse é um projeto seu? A experimentação, tentar coisas novas, colocar todas essas coisas juntas, foram movimentos intencionais ou só a maneira como você escreve, por exemplo?

MT | Não sei responder, quero dizer, acho que um pouco de ambos. Eu penso nessa questão como referente à honestidade. Honestidade com a situação, particularmente... você sabe, é uma tríade. Acho que o [Edward] Said fala disso no seu livro The World, the Text and the Critic: tem um mundo, tem um autor, tem um leitor e tem um ser honesto nesta situação.

5-É engraçado que você mencione o Timerman, e o Timerman foi uma referência que li por conta do Xamanismo. Eu lembro de você mencionar durante a sua disciplina - "Taboo and Transgression" - que quando escrevemos sobre a violência, temos uma única chance. Logo depois você falou do Timerman, sobre a tortura e a ditadura na Argentina e como na tortura conseguimos encontrar o sadismo e não só a declaração estatal oficial sobre descobrir a "verdade" ou estabelecer e garantir a ordem. Eu também me lembro dos sentimentos que experimentei ao ler Xamanismo, colonialismo e o homem selvagem: como eu conseguia sentir as atrocidades e as crueldades que você descreve usando relatos como aqueles de Timerman ou que estão no Relatório de Casement ${ }^{5}$. Neste momento, você nos fornece dois conceitos: o "espaço da morte" e a "cultura do terror". Vemos essas questões novamente quando você descreve a "limpieza" na Colômbia (em Law in a Lawless Land) muitos anos depois, por exemplo. Ou quando vocêfala sobre a Polícia de Nova lorque no texto NYPD Blues ${ }^{6}$. O que você quer dizer quando fala que temos
4 | Os textos mencionados são "Sobre a autoridade etnográfica" e "Sobre o surrealismo etnográfico". Ambos foram traduzidos no livro A Experiência Etnográfica.

5| Relatório apresentado por Roger Casement ao British Foreign Service em 1913. Também chamado de Relatório sobre o Putumayo, este documento é uma das bases utilizadas por Taussig na parte inicial de Xamanismo, Colonialismo e o Homem Selvagem para descrever as atrocidades cometidas contra os indígenas do Putumayo em meio à exploração colonial de borracha.

6| TAUSSIC, M. NYPD Blues. In: Walter Benjamin's Crave. Chicago/London: University of Chicago Press, 2006. 


\section{uma única chance ao escrever sobre a violência? Como enquadramos a violência e o terror hoje, especialmente se pensarmos que o terror necessita da ordem para funcionar?}

MT |A minha sensação é que escrever sobre a violência, escrever contra a violência, é perigoso porque isso ajuda e estimula a violência dentro do autor, assim como a violência no leitor, e um certo nível de estimulação como essa eu acredito que seja necessária para pensar na violência de forma opositora, mas é uma força que provavelmente será autodestrutiva. É uma força que provavelmente irá exceder a crítica. O conteúdo, por assim dizer, suplanta a crítica. Eu sentia que não era algo que poderia ser prolongado, uma única tentativa era mais do que suficiente, era isso que sentia. Eu tenho, contudo, desobedecido a minha própria regra algumas vezes e não sei o que dizer sobre isso. Integrar a estimulação fornecida pela violência à crítica foi uma das minhas ideias, talvez excêntricas, de que os tópicos, coisas, fatos como a violência estimulam a função mimética da linguagem, e é por isso que são tão perigosos, porque eles estimulam as palavras; e as frases se tornam aquilo que elas descrevem. Então não se escreve sobre a violência como se ela fosse algo, um objeto lá fora. O objeto é animado, o objeto se torna o sujeito, ele confronta o sujeito que está escrevendo e tudo isso toma conta do consciente do leitor. É por conta dessa habilidade da violência em fundir, em misturar as palavras com aquilo que elas significam. É assim que eu acredito que a coisa funcione, e isso aciona algo muito importante. Ademais, um terceiro ponto que eu consigo ver é a violência se tornando um tópico na moda, um tópico acadêmico, algo em que se pode construir uma carreira, e eu não queria me envolver com isso. Eu queria dar um passo para longe disso, ao mesmo tempo, sem sancionar a ideia de que se deve manter-se calado. Sabe aquela referência famosa ao Adorno depois de Auschwitz? A ideia de "sem poesia"? Isso me parece bastante equivocado, e aquele livro sobre Auschwitz argumenta isso. Claro, o texto dele é bastante especial. Ninguém chegou perto de algo assim. Devem existir, mas desconheço. Se eu consigo pensar em algo parecido seria em Darwish ${ }^{7}$, um poeta palestino, e seu relato sobre a ocupação, a invasão de Beirute por Israel em 1982. Essas

7| Taussig se refere ao poeta Mahmoud Darwish. não são pessoas que dizem que você precisa se manter em silêncio, ou que é melhor ficar em silêncio, certo? Então, esses são trabalhos de alta qualidade, com altos padrões, você sabe. Darwish é um poeta, Primo Levi era um químico que estava interessado nos fatos, mas que tinha uma alma de poeta e conseguiu produzir esse trabal ho altamente eficiente. Voltando ao ponto inicial que argumentava sobre a ideia de escrever sobre a violência. Principalmente, falar da violência, da violência desonesta, barateia a violência, e é muito difícil não fazer isso. Você torna qualquer apelo ou referência à compaixão sem função. Portanto, em termos pragmáticos, é contestável. 
6-Quero voltar à discussão sobre os atos de ler e de escrever. Minha impressão é que você está enfatizando estes atos como práticas ritualísticas (ou, como você lindamente postulou, "palavras como elos para o visceral, para a concretude das coisas conectadas por meio de correntes de existência"). Ao mesmo tempo, você nos lembra da instabilidade do sentido, e, claro, da interpretação. Você fala do sistema nervoso, do baile de máscaras e do segredo, e nos traz uma comparação que até hoje me surpreende: a realidade como um jogo de $\operatorname{copos}^{8}$ (é a desordem da ordem, é outra vez a transgressão). Como podemos compreender essas coisas juntas? Há uma estratégia ou caminho para que os leitores compreendam que nós estamos lá (fazendo pesquisa, fazendo campo) e, ao mesmo tempo, que eles leiam como se o texto estivesse na terceira pessoa? E preciso repetir que eu acredito que você tem domínio desse processo e que consegue nos fazer sentir de muitas formas aquilo que descreve. Lembro-me da forma como você inicia The Corn Wolf: "ninguém disse a ela ou ele (1) como realizar a pesquisa de campo ou (2) que a escrita é quase sempre a parte mais difícil do processo". Então, como você vê essas questões: a realidade como um jogo de copos, e o processo de escrita e leitura?

MT | Bom, eu me sinto feliz ao falar dessa última parte da sua questão, ou seja, sobre a falta de atenção à escrita somada à falta de atenção ao trabalho de campo. Nos programas de doutorado em antropologia, os alunos devem cuidar de si mesmos. Eu sei que existem exceções. Departamentos diferentes em momentos diferentes talvez falem bastante sobre o campo, sobre como fazê-lo de forma criativa. Mas na minha experiência, nunca me ensinaram sobre como fazer campo, e eu sempre gostei do que Laura Bohannan falou enquanto vivia em Oxford. Ela foi orientada a usar sapatos de andar na areia, pois esses deixam a água escorrer, ou "não durma com os nativos", ou algo assim?. Talvez não falaram explicitamente e essa é a segunda dica. Mas basicamente você precisa descobrir tudo sozinho. Eeu acredito que a combinação de não dar grande importância à escrita e de não dar atenção ao trabalho de campo, os dois juntos, esses são os aspectos mais importantes de um antropólogo e isso me parece particularmente estranho... Claro, não precisa literalmente ensinar... Eu acho que você não consegue ensinar escrita; acho que não é possível ensinar a fazer o trabalho de campo. Toda situação é diferente e assim por diante. Mas você pode ter discussões maravilhosas sobre elas. Você pode pensar na escrita pela escrita, não? Então, essa é a essência, esse era o ponto de partida das questões que resultaram no ensaio sobre o Corn Wolf. Mas você iniciou com uma pergunta sobre o jogo de copos e a realidade, e eu acredito que isso adveio do meu interesse pela escrita como parte da realidade, e a realidade é em grande parte composta por performance e pretensão. Ese percebe isso, mas também se percebe que você não pode mudar isso, você não pode mudar as regras do jogo no meio do caminho. Então, como posso dizer isso... tem uma dupla consciência
8 | Em inglês o termo usado é "shell game", o que em português equivale ao chamado jogo/truque de copos mágicos, em que um objeto é ocultado por um copo e o desafio é adivinhar, após os copos serem mexidos e remexidos, onde este objeto se encontra.

9|A história mencionada por Taussig está no livro Return to Laughter, de Eleonore Smith Bowen (pseudônimo de Laura Bohannan). 
em jogo nessa brincadeira com a linguagem, todos nós estamos jogando esse jogo de fantasia. Estamos performando essa realidade na nossa escrita, nas nossas discussões. Mas aí não podemos mudar de função quando percebemos que, quando ficamos hiper-conscientes, se poderia dizer, ou o outro lado da consciência, que esse é um jogo e que deixamos que isso interfira. E esse é o jogo de copos: você troca o item debaixo do copo e depois volta novamente. Em The Nervous System, que foi escrito bem no começo, por volta de 1988-89, o tropo que eu usava era "o sistema que estava nervoso", ou seja, o sistema nervoso, e eu estava argumentando que esse sistema é nervoso. "Um sistema nervoso nervosamente nervoso" é também histérico e perigoso porque está a ponto do colapso e, portanto, uma energia estranha está atuando no "sistema nervoso nervosamente nervoso". Os componentes que selecionei foram a ordem e a desordem que o nosso trabalho como antropólogo, cientista social particularmente, era buscar a razão, dar explicações, colocar fatos heterogêneos em algum tipo de ordem homogênea. Mas assim que o fizer, você precisa ter autopercepção, você precisa ter a inteligência de perceber que essa é uma coisa arbitrária, e pode entrar em colapso e retornar à desordem. Mas então, assim que você aceita a desordem, você diz: essa é a natureza da realidade, essa é a natureza do mundo, essa é a natureza da história. Aí o mundo vai falar com você e dizer "não, eu enganei você, aquele mundo até tem uma ordem", pode ser Deus, talvez seja "a economia". Enfim, então você volta correndo para o polo da ordem só para então atingir um limite e ser jogado de volta, e então dizer: não, não há ordem, essa é uma pretensão, é tudo desordem. Então se caminha, talvez de forma patética ou divertida, entre esses dois pólos. Isso, eu acho, resume o jogo de copos.

7-Outra coisa que gostaria de discutir é como você brinca com as palavras e o uso que faz das ambiguidades, oposições, e contradições (ordem e desordem, para usar seus termos). A primeira é o terror e a cura, mas conseguimos encontrar algo similar na palavra ambígua limpeza (como violência e como cura espiritual). Às vezes, acho que você é como o bricoleur do Lévi-Strauss, brincando com a ciência e a magia das palavras (mas acredito que você preferiria ser comparado com o colecionador do Benjamin), criando nesse processo um museu de palavras e sentidos, produzindo de fato um museu não canônico (parecido com o que fez em My Cocaine Museum). Fazendo referência a Wittgenstein, você disse "toda uma mitologia está depositada em nossa linguagem". Então, qual a sua mitologia e como isso se conecta com seu projeto antropológico?

MT | Muito bem colocado. Essa seria uma figura mais apropriada para me comparar, mais do que o Benjamin. Apesar de que Benjamin estava bastante envolvido no misticismo da linguagem e com sua série de traduções. Mas essa é uma figura 
mais agradável, eu acredito, nesse sentido. Então, qual seria a minha mitologia? Minha mitologia está, eu acredito, claramente articulada no prefácio do meu livro Mimesis and Alterity, principalmente no final quando digo "tente imaginar um mundo em que a ciência é natural, e tente imaginar um mundo em que a ciência fosse não-natural ou sem motivação, como disse Saussure. Ambos seriam igualmente impossíveis de imaginar. Ambos se autodestroem depois de se contemplar sobre esses extremos. Foi aí que pensei na faculdade mimética e também no jogo de copos, que se tornou fascinante e algo que se quer praticar na própria escrita. Então, minha mitologia seria essa: o que eu chamo de faculdade mimética que é, se preferir, quando uma magia da antiguidade se envolve. Então essa é a mitologia: você se envolve com a série pós-estruturalista da linguagem.

\section{8-Xamanismo, colonialismo e o homem selvagem é o motivo pelo qual eu vim à Nova} lorque. Acho que as suas proposta sobre a "cultura do terror" e o "espaço de morte" são convites para interpretar a vida social hoje, num momento em que falamos sobre novas formas de genocídio, necropolítica e neofascismo. Quando lemos a primeira parte do Xamanismo, que você intitulou de "Terror" - é como se não houvesse saída, como Kurtz diz em Coração das trevas: "o horror, o horror". Mas aí há essa segunda parte, sobre a cura (quando a cura se torna a esperança, talvez), existe uma contradição no sistema. Podemos pensar na escrita como um processo de cura?

MT | Ah sim, claro. Absolutamente! É por isso que escrevo tanto. Um processo constante de terapia, de autocura. A música que um xamã canta, ou a música que os xamãs produzem com suas gargantas e seu peitoral também estão nessa categoria. Pode-se dizer que se está evocando os espíritos se quiser, e assim por diante. Mas eu acho que a cura é mais do que suficiente. A escrita é uma forma de evocar a voz, ou vozes, nas nossas cabeças que falam por si mesmas por meio da gente, e essa é a ideia xamânica, se quiser, de que há uma força fora de você. Você poderia chamar de fatos sociais, história, tradição, e assim por diante, que o escritor catalisa quando se depara com um problema ou desafio particulares. A beleza é que isso é terapêutico. Mas não quero dar muita ênfase, contudo, ao aspecto terapêutico, em parte porque eu acredito que seja verdade e que não se deve mexer com isso. Eu acho que isso é frágil e, uma vez que se está consciente disso, pode se tornar um problema. Eu quero dar ênfase ao amor pela invenção, ao amor por fazer. Como fazer uma peça de teatro, como fazer música, como fazer uma pintura... só criar alguma coisa é um aspecto importante que constitui, não sei. la dizer a humanidade, mas essa palavra é muito grande, com pessoas diferentes em momentos diferentes da história. Se me lembro corretamente, o final da primeira parte do livro Xamanismo termina num momento de mistério, de ofuscação, porque eu aceito o desafio antropológico, que é o ponto de vista nativo. É o grande tropo autoritário da antropologia, que você descobriu o ponto 
de vista do nativo. Tem muito a ser criticado nessa frase, mas, no livro Xamanismo, a única evidência que eu tinha do ponto de vista nativo sobre as pessoas que foram torturadas era de dois antropólogos que me disseram que aqueles indígenas contaram a eles, os desafiaram: "por que você quer saber sobre essas atrocidades? Apenas feiticeiros querem saber sobre isso, e com essa informação eles fazem coisas más". Então era como se você dissesse que quer saber o ponto de vista nativo, e o ponto de vista do nativo é "não queira saber sobre isso" e isso para mim foi um choque tremendo em vários níveis. Uma especificamente, acho que descrevi pra você anteriormente, tinha a ver com isso. Voltando para a sua pergunta sobre ter apenas uma chance para escrever sobre a violência, havia um ponto de vista aqui, quase uma ordem, um comando, de não se perguntar sobre certas coisas. E isso me parecia ir de encontro com o lluminismo, que é esse grande conceito acadêmico que tudo e qualquer coisa pode ser examinado e discutido, e obviamente havia uma barreira sendo colocada, e eu achava os motivos muito plausíveis. Quando deparado com esse motivo - a razão em si- não se pode menosprezá-lo; você não pode perguntar sobre isso porque isso é o que os feiticeiros fazem. Eu acho que essa é uma maneira muito melhor de responder sua pergunta, sobre a delicadeza de se indagar sobre quão horrorosos os humanos podem ser uns com os outros.

9- Para finalizar, gostaria de explorar a ideia do seu próximo livro. Claro, não o li ainda, mas o título nos dá algo para pensar: 0 domínio do não-domínio ${ }^{10}$ numa era de colapso. Se me recordo corretamente, você usa essa ideia pela primeira vez em Walter Benjamin's Grave, relacionando-o com o conceito de soberania do Bataille (naquilo que Bataille retira de Nietzsche). Em um manuscrito de 2017, você nos convida a refletir sobre o processo de exploração da natureza e de nós mesmos, clamando por mutualidade (e não exploração) num contexto de caos global. Os fatos recentes (e estamos vivenciando um deles com a pandemia do coronavírus) confirmam esse colapso. No seu argumento, novamente vimos algumas das ideias que guiam o seu trabalho: mimética (ou a faculdade mimética), o espaço da morte, natureza não como colônia e vítima, mas respondendo e revidando (como vimos em Palma africana", por exemplo). Com isso em mente, (e a inspiração em Nietzsche-"saber aquilo que não devemos saber"), como você entende o domínio do não-domínio?

MT | Ah, isso é muita coisa (risos). "Saber aquilo que não devemos saber" é uma formulação curiosa, claro, é uma questão tentadora. Eu a interpretaria agora, nessa conversa com você, no sentido de deixar algumas coisas inconscientes. Se você volta no tema do antropólogo falando com os povos indígenas mais velhos sobre tortura em Putumayo e eles dizem "não pergunte sobre isso, isso é apenas para os feiticeiros, porque você quer saber?", o inconsciente se sobrepõe
10| O livro Mastery of nonmastery in the age of meltdown foi lançado em julho de 2020 .

11 | TAUSSIC, M. Palma africana. Chicago: University of Chicago Press, 2018. 
a isso. Eles sabiam aquilo que "não se deve saber", quero dizer, e saber "o que não se deve saber" em si só é altamente paradoxal, pois de alguma forma se sabe o que não se deve saber. Você fica louco! É um pouco como o domínio do não-domínio, quero dizer, você fica doido. Então a tarefa do mutualismo, de não dominar a natureza, envolve esse tipo de incrível ginástica mental e visceral, de saber aquilo que não se deve saber, desse domínio do não-domínio, do apelo para o aspecto inconsciente da natureza e o inconsciente da humanidade - para desenvolver e criar conhecimento habitual, que é como de uma segunda natureza, aquilo que você faz sem pensar de forma consciente. Como transitar da consciência para esse estado de coisas, essa é outra enorme questão. Isso obviamente envolve o que hoje chamamos de anticolonialismo, as qualidades racializadas e generificadas da história e das condições atuais. Me parece que essas histórias humanas, relacionamentos humanos, estão em muitos casos no centro daquilo que é necessário para um confronto ambientalista, sabe? E isso não é óbvio em tudo o que dissemos, mas deveria ser.

Carolina Parreiras é pesquisadora de pós-doutorado do Departamento de Antropologia da USP e professora colaboradora do Programa de Pós-graduação em Antropologia Social da Unicamp. É integrante do NUMAS/USP - Núcleo de Estudos sobre Marcadores Sociais da Diferença. Foi Visiting Scholar do Institute of Latin American Studies (ILAS), da Columbia University, supervisionada pelo professor Michael Taussig. A pesquisa que deu origem a essa entrevista contou com financiamento da Fundação de Amparo à Pesquisa do Estado de São Paulo - FAPESP (processo n. 2019/00897-7).

\section{REFERÊNCIAS BIBLIOGRÁFICAS}

TAUSSIG, Michael. 1987. Xamanismo, colonialismo e o homem selvagem. Um estudo sobre o terror e a cura. São Paulo, Paz \& Terra.

TAUSSIG, Michael. 1992. The Nervous System. New York/London, Routledge.

TAUSSIG, Michael. 1993. Mimesis and Alterity: a particular history of the senses. New York/London, Routledge.
TAUSSIG, Michael. 1997. The Magic of the State. New York/London, Routledge.

TAUSSIG, Michael. 2003. Law in a Lawless Land. Diary of a limpieza in Colombia. Chicago/ London, University of Chicago Press.

TAUSSIG, Michael. 2004. My Cocaine Museum. Chicago/London, University of Chicago Press. 
TAUSSIG, Michael. 2006. Walter's Benjamin Crave. Chicago/London, University of Chicago Press.

TAUSSIC, Michael. 2011. I swear I saw this. Drawings in fieldwork notebooks, namely my own. Chicago/London, University of Chicago Press.

TAUSSIG, Michael. 2015. The Corn Wolf. Chicago/London, University of Chicago Press.
TAUSSIG, Michael. 2018. Palma Africana.

Chicago, University of Chicago Press.

TAUSSIG, Michael. 2020. Mastery of nonmastery in the age of meltdown. Chicago/ London, University of Chicago Press.

SAID, Edward. 1983. The World, the Text and the Critic. Cambridge, Harvard University Press.

TIMERMAN, Jacobo. 1981. Prisoner

Without a Name, Cell Without a Number. New York, Alfred A. Knopf. 